\title{
Rates, Sites and Times of Recurrence and Clinical Outcome of Endometrial Cancer Patients with Histologically-positive Nodes: An Italian Two-center Retrospective Study
}

\author{
ANGIOLO GADDUCCI ${ }^{1}$, MARIA ELENA GUERRIERI ${ }^{1}$, STEFANIA COSIO $^{1}$, MARIA GRAZIA FABRINI ${ }^{2}$, \\ CONCETTA LALISCIA ${ }^{2}$, DANIELA ATTIANESE ${ }^{3}$, ANNALISA ROSSI ${ }^{4}$ and ANNAMARIA FERRERO ${ }^{3}$ \\ ${ }^{1}$ Department of Experimental and Clinical Medicine, \\ Division of Gynecology and Obstetrics, University of Pisa, Pisa, Italy; \\ ${ }^{2}$ Department of Oncology, Division of Radiation Oncology, University of Pisa, Pisa, Italy; \\ ${ }^{3}$ Academic Department of Gynecology and Obstetrics, University of Torino, Mauriziano Hospital, Turin, Italy; \\ ${ }^{4}$ Division of Radiation Therapy, Mauriziano Hospital, Turin, Italy
}

\begin{abstract}
Background/Aim: To assess the patterns of recurrence of node-positive endometrial cancer patients. Patients and Methods: This investigation assessed 82 patients who received different postoperative treatments. Results: Recurrence developed in 36 patients after a median time of 13.5 months, and involved the vagina, pelvic nodes, para-aortic nodes and distant sites in 5, 8, 16 and 17 patients, respectively. Five-year progression-free survival $(P F S)$ and 5-year overall survival (OS) were $51.1 \%$ and $59.8 \%$. PFS and OS were significantly better for endometrioid than for non-endometrioid tumors. There was a trend towards a better outcome for patients who underwent chemotherapy \pm radiotherapy compared to those who received radiotherapy alone. Among the former, there was a better 5 -year PFS (65.8\% versus $33.7 \%, p=0.038)$ in patients who received platinum/paclitaxel-based regimens compared to those who received platinum-based chemotherapy. Conclusion: Disease recurred in $43.9 \%$ of patients, and platinum/paclitaxel-based chemotherapy plus radiotherapy appeared to be the best adjuvant treatment.
\end{abstract}

The standard surgery of endometrial cancer consists of total hysterectomy with bilateral salpingo-oophorectomy carried out with open or mini-invasive approach, whereas the role and the extension of retroperitoneal node dissection is still

Correspondence to: Angiolo Gadducci, Department of Clinical and Experimental Medicine, Division of Gynecology and Obstetrics, University of Pisa, Via Roma 56, Pisa, 56127, Italy. Tel: +39 50992609, Fax: +39 50553410, e-mail: a.gadducci@med.unipi.it

Key Words: Endometrial cancer, lymphadenectomy, node metastases, patterns of failures, radiotherapy, chemotherapy. debated (1-5). Node metastases can be found in approximately $10 \%$ of women with apparently early stage endometrial cancer at the preoperative work-up, and systematic lymphadenectomy should be an integral part of the International Federation of Gynecology and Obstetrics [FIGO] staging system, useful for the definition of prognosis and planning of adjuvant therapy (6-8). However, the therapeutic benefit of this surgical procedure is still uncertain. Two randomized trials failed to detect any advantage in progression-free survival (PFS) and overall survival (OS) for patients who underwent pelvic lymphadenectomy compared to those who did not, although these trials had been criticized for several biases (9-11). Moreover, the women in the lymphadenectomy arm experienced a higher risk of surgeryrelated systemic morbidity and lymphoedema/lymphocyst formation. As suggested by the Mayo Clinic historical surgical algorithm $(12,13)$, lymphadenectomy should be carried out in patients with apparent stage I endometrioid endometrial cancer and grade 3 on preoperative biopsy and/or myometrial invasion $\geq 50 \%$ on intraoperative frozen sections of the uterine specimen as well as in patients with nonendometrioid tumors, whereas this surgical procedure can be omitted in endometrioid endometrial cancer patients with no myometrial invasion (regardless of grade or tumor diameter) or with grade $1-2,<50 \%$ myometrial invasion and tumor diameter $\leq 2 \mathrm{~cm}$. The sentinel lymph node biopsy is considered to be experimental by the ESMO-ESGO-ESTRO Consensus Conference on endometrial cancer (3), whereas it has been included in the National Comprehensive Cancer Network (NCCN) guidelines for this malignancy (14).

Among the 7,990 surgically staged endometrial cancer patients reported in the FIGO annual Report n. 26, 356 (4.5\%) had stage IIIc disease, and their 5-year OS was $57.3 \%$ (6). Radiotherapy and chemotherapy have been 
Table I. Treatment modalities.

\begin{tabular}{lc}
\hline & Patients \\
\hline Type of hysterectomy & \\
I & $53(64.6 \%)$ \\
II & $29(35.4 \%)$ \\
Pelvic lymphadenectomy & \\
Performed & $82 / 82(100 \%)$ \\
Adequate (>10 removed nodes) & $67 / 82(81.7 \%)$ \\
Number of removed nodes (median, range) & $15(3-50)$ \\
Para-aortic lymphadenectomy & \\
Performed & $38 / 82(46.3 \%)$ \\
Adequate & $25 / 38(65.8 \%)$ \\
Number of removed nodes (median, range) & $7(2-27)$ \\
Adjuvant treatment & $10(12.2 \%)$ \\
Pelvic EBRTa & $1(1.2 \%)$ \\
BCT & $21^{\mathrm{c}}(25.6 \%)$ \\
CT* & $50^{\mathrm{d}}(61.0 \%)$ \\
CT**+ pelvic EBRT & \\
\hline
\end{tabular}

aBCT added in 1 ; VBT + para-aortic irradiation added in $1 .{ }^{\mathrm{b}} \mathrm{BCT}$ added in 6; para-aortic irradiation added in 7; $\mathrm{BCT}+$ para-aortic irradiation added in 1. ${ }^{\text {PTX }}\left(175 \mathrm{mg} / \mathrm{m}^{2}\right)+$ CBDCA (AUC 5) q 21 in 6; EPIDOX $\left(80 \mathrm{mg} / \mathrm{m}^{2}\right)+\operatorname{PTX}\left(175 \mathrm{mg} / \mathrm{m}^{2}\right)+\operatorname{CDDP}\left(75 \mathrm{mg} / \mathrm{m}^{2}\right) \mathrm{q} 21$ in 10 ; DOX $\left(60 \mathrm{mg} / \mathrm{m}^{2}\right) /$ EPIDOX $\left(80 \mathrm{mg} / \mathrm{m}^{2}\right)+\operatorname{CDDP}\left(50-75 \mathrm{mg} / \mathrm{m}^{2}\right) \mathrm{q} 21$ in 3 ; CDDP $\left(75 \mathrm{mg} / \mathrm{m}^{2}\right) / \mathrm{CBDCA}$ (AUC5) $\mathrm{q} 21$ in 2 . dPTX $\left(175 \mathrm{mg} / \mathrm{m}^{2}\right)$ +CBDCA (AUC 5) q21 in 28; EPIDOX $\left(80 \mathrm{mg} / \mathrm{m}^{2}\right)+$ PTX $\left(175 \mathrm{mg} / \mathrm{m}^{2}\right)$ $+\operatorname{CDDP}\left(75 \mathrm{mg} / \mathrm{m}^{2}\right)$ q 21 in 5 ; DOX $\left(60 \mathrm{mg} / \mathrm{m}^{2}\right) /$ EPIDOX $\left(80 \mathrm{mg} / \mathrm{m}^{2}\right)+$ CDDP $\left(50-75 \mathrm{mg} / \mathrm{m}^{2}\right)$ q 21 in 14; Other platinum-, anthracycline-based $\mathrm{CT}$ in 3 . *mean number of $\mathrm{CT}$ cycles $=5.6$ (range $=4-6$ cycles). $* *$ mean number of $\mathrm{CT}$ cycles=4.5 (range=3-6 cycles). EBRT: External beam irradiation; BCT: brachytherapy; CT: chemotherapy; PTX: paclitaxel; CBDCA: carboplatin; EPIDOX: epidoxorubicin; CDDP: cisplatin; DOX: doxorubicin.

widely used as postoperative treatments, but no definitive conclusion can be drawn on the optimal adjuvant therapy in this clinical setting $(3,11,13,15-34)$.

The purpose of this retrospective investigation was to analyze the rates, sites and times of recurrences and the clinical outcome of patients with FIGO stage $\mathrm{III}_{\mathrm{c} 1}-\mathrm{III}_{\mathrm{c} 2}$ endometrial cancer treated at two Italian Gynecological Oncology centers.

\section{Materials and Methods}

This retrospective investigation assessed 82 patients who underwent peritoneal washing, extrafascial (Piver-Rutledge class I) or modified radical (Piver-Rutledge class II) hysterectomy, bilateral salpingooophorectomy and pelvic plus aortic lymphadenectomy for endometrial cancer and who had histologically proven positive nodes at the Department of Gynecology and Obstetrics of the University of Pisa between 1993 and 2016 and the Department of Gynecology and Obstetrics of the University of Turin (Mauriziano Hospital) between 2003 and 2016. The patients who did not undergo aortic lymphadenectomy had negative computed tomography (CT)
Table II. Primary sites of failure.

\begin{tabular}{lc}
\hline Site of failure & Number \\
\hline Distant & $12 *(33.3 \%)$ \\
Pelvic N & 2 \\
Para-aortic N & $12(2$ with concomitant pelvic N) \\
Vaginal & $4(11.1 \%)$ \\
Multiple & $6^{* *(16.7 \%)}$ \\
Total & $36 / 82(43.9 \%)$ \\
\hline
\end{tabular}

*Peritoneum, 5; lung, 3; lung + liver, 2 ; lung + liver + peritoneum, 1 ; bone, 1. **Para-aortic $\mathrm{N}+$ pelvic $\mathrm{N}+$ liver, 1 ; para-aortic $\mathrm{N}+$ pelvic $\mathrm{N}+$ mediastinic $\mathrm{N}, 1$; para-aortic $\mathrm{N}+$ mediastinic $\mathrm{N}$ in 1 ; para-aortic $\mathrm{N}$ + peritoneum in 1 ; vagina + pelvic $\mathrm{N}+$ peritoneum in 1 ; vagina + pelvic N, 1. N: Nodes.

findings for node aortic involvement. Abdomen-pelvis CT scan was performed two to three weeks before surgery, and aortic nodes were defined negative when their short axes were $<5 \mathrm{~mm}$. Some of the patients treated in Pisa had been included in a previous paper of our group (35).

Sixty-seven women were operated via laparotomy and 15 via minimally invasive approach (laparoscopy or robotics). Women with carcinosarcoma were excluded from the present analysis. According to Mariani et al. (13), an adequate pelvic lymphadenectomy was defined as the removal of $>10$ pelvic nodes, and an adequate para-aortic lymphadenectomy was defined as the removal of $\geq 5$ para-aortic nodes.

Patients were staged retrospectively according to the FIGO 2009 classification (7).

The architectural grade was defined as follows: $\mathrm{G}_{1}, \leq 5 \%$ of nonsquamous or non-morular solid growth pattern; $\mathrm{G}_{2}, 6-50 \%$ of nonsquamous or non-morular solid growth pattern; and $\mathrm{G}_{3},>50 \%$ of non-squamous or non-morular solid growth pattern. Notable nuclear atypia, inappropriate for the architectural grade, raised the grade of $\mathrm{G}_{1}$ or $\mathrm{G}_{2}$ tumor by one.

Lymph-vascular space involvement (LVSI) was defined as the presence of tumor cells within or attached to the wall of a blood vessel or lymphatic space using morphological and immunohistochemical analyses.

Post-operative treatment was established on the basis of pathological findings on surgical specimens, patient age and general conditions. However, adjuvant therapy has been changed in the two centers over the long interval time of the study.

External-beam radiotherapy (EBRT) was performed with a 15-18 MV beam, and a 45-50.4 Gy dose was given to the pelvis in daily fractions of $1.8 \mathrm{~Gy}$ in 5-6 weeks. The target volume was outlined on a CT scan. When performed, 45 Gy para-aortic irradiation was planned in daily fractions of $1.8 \mathrm{~Gy}$ in 5 weeks. Vaginal cuff highdose rate brachytherapy (BCT) was added in selected cases with isthmus or stromal cervical involvement after EBRT. The prescribed dose was 10-15 Gy in 5 Gy fractions. Rectal and bladder doses were estimated from dose volume histograms on CT-based plans and were evaluated to the dose points specified by the International Commission on Radiation Units and Measurements.

Adjuvant chemotherapy consisted of platinum-based regimens. EBRT was delivered sequentially after chemotherapy in patients who received both adjuvant treatments. 
Table III. Treatment and clinical outcome of patients with recurrent disease.

\begin{tabular}{|c|c|c|}
\hline Failure site & Treatment Pts & Clinical outcome \\
\hline \multirow[t]{4}{*}{ Distant (n.12) } & CT: 7 & 7 DOD after a median of 9.5 months (range $=2.7-13.3$ ) \\
\hline & SUa + CT: 2 & 1 DOD after 53.3 months; 1 NED after 52 months \\
\hline & $\mathrm{CT}+\mathrm{RT}: 1$ & 1 DOD after 5 months \\
\hline & No therapy: 2 & 1 DOD after 1 week; 1 DOD after 2 months \\
\hline \multirow[t]{6}{*}{ Retroperitoneal N (n.14) } & CT: 5 & 5 DOD after a median of 11.5 months (range $=5.1-17$ months) \\
\hline & $\mathrm{CT}+\mathrm{RT}: 4$ & 3 DOD after 32 months (range $=8.1-39.6$ months); 1 NED after 5 months \\
\hline & RT: 2 & 1 DOD after 56.7 months, 1 NED after 24.9 months \\
\hline & $\mathrm{SU}^{\mathrm{b}}+\mathrm{CT}: 1$ & DOD after 11.3 months \\
\hline & SUc: 1 & DOD after 5.2 months \\
\hline & No therapy: 1 & DOD after 25.1 months \\
\hline \multirow[t]{3}{*}{ Vaginal (n.4) } & RT: 2 & 2 DOD after 7.7 months and 27.2 months \\
\hline & $\mathrm{SU}^{\mathrm{d}}+\mathrm{CT}: 1$ & DOD after 11.8 months \\
\hline & No therapy: 1 & DOD after 1.9 months \\
\hline \multirow[t]{5}{*}{ Multiple (n.6) } & CT + RT: 2 & 2 DOD after 26.3 and 49.7 months \\
\hline & $\mathrm{SU}^{\mathrm{e}}+\mathrm{CT}: 1$ & DOD after 62.8 months \\
\hline & $\mathrm{RT}+\mathrm{HT}: 1$ & DOD after 10.2 months \\
\hline & CT: 1 & DOD after 6.1 months \\
\hline & HT: 1 & DOD after 13.2 months \\
\hline
\end{tabular}

aLiver resection,1; blung resection; ${ }^{\mathrm{N}}$ resection; $\mathrm{d}_{\text {colpectomy; }}{ }^{\mathrm{e}}$ colpectomy+rectal resection. Pts: Patients; CT: chemotherapy; DOD: dead of disease; SU: surgery; NED: no evidence of disease; RT: radiotherapy, HT: hormone therapy; N: nodes.

Follow-up procedures are reported in a previous paper (36). All the patients were periodically followed until September 2017 or until death. The median follow-up of survivors was 66.9 months (range=8.0-207.8 months).

Statistical analysis. Age, FIGO stage (IIIC 1 versus $\mathrm{IIIC}_{2}$ ), tumor grade $\left(\mathrm{G}_{1-2}\right.$ versus $\left.\mathrm{G}_{3}\right)$, histology (endometrioid versus nonendometrioid), myometrial invasion ( $<50 \%$ versus $\geq 50 \%$ ), LVSI, cervical involvement, adnexal involvement, type of radical hysterectomy (I versus II), adjuvant treatment (chemotherapy+ EBRT versus chemotherapy versus radiotherapy alone), and chemotherapy regimen (platinum/ paclitaxel-based versus platinumbased) were analysed for association with PFS and OS. Peritoneal, hematogenous, and node recurrences outside the retroperitoneal area (i.e. mediastinal) were considered as distant failures.

SAS statistical package (release 8.2; SAS Institute, Cary, NC, USA) was used for the computations.

The time from surgery to the detection of recurrence was defined as PFS. The time from surgery to death or last observation was defined as OS. The cumulative probability of PFS and OS were estimated by the product-limit method. The log-rank test was used to compare the homogeneity of PFS and OS functions across strata defined by categories of prognostic variables.

\section{Results}

At presentation, median age of patients was 64 years (range $=36-85$ years). FIGO stage was IIIC1 in $54(65.9 \%)$ and $\mathrm{IIIC}_{2}$ in $28(34.1 \%)$ women. Tumor grade was $\mathrm{G}_{1}$ in 5 $(6.1 \%), \mathrm{G}_{2}$ in $33(40.2 \%)$, and $\mathrm{G}_{3}$ in $44(53.7 \%)$ patients, respectively. Histological type was endometrioid in 58 $(70.7 \%)$ and non-endometrioid in 24 (29.3\%) women (serous, 14; clear cell, 4; undifferentiated, 6). Myometrial invasion $\geq 50 \%$, LVSI, cervical involvement, and adnexal involvement were found in $70(85.4 \%), 58(70.7 \%), 24$ $(29.2 \%)$, and $18(21.95 \%)$ patients, respectively. Treatment modalities are reported in Table I.

Pelvic lymphadenectomy was performed in all 82 women, and positive pelvic nodes were found in 77 (93.9\%). The median number of metastatic pelvic nodes was 2 (range $=1$ 21 nodes). Para-aortic lymphadenectomy was performed in 32 of these 77 patients, and positive para-aortic nodes were found in $21(65.6 \%)$.

Para-aortic lymphadenectomy was performed in 38 out of the 82 patients, and positive para-aortic nodes were found in $26(68.4 \%)$. The median number of metastatic para-aortic nodes was 2 (range $=1-17$ para-aortic nodes). The pelvic nodes were positive in 21 of these 26 patients $(80.8 \%)$.

Postoperative treatment consisted of chemotherapy in 21 women $(25.6 \%)$, chemotherapy followed by EBRT in 50 $(61.0 \%)$, EBRT in $10(12.2 \%)$, and BCT alone in one $(1.2 \%)$.

Tumor relapsed in 36 out of the 82 patients $(43.9 \%)$, with a median time to recurrence of 13.5 months (range $=4.1$ to 35.2 months). Overall, recurrent disease involved vagina in

$5(6.1 \%)$, pelvic nodes in $8(9.8 \%)$, para-aortic nodes in $16(19.5 \%)$, and distant sites in $17(20.7 \%)$, respectively, of the 82 patients (Table II).

Recurrent disease had a very poor prognosis (Table III). Eleven of the $12(91.7 \%)$ patients with distant failure, 12 of the 14 patients $(85.7 \%)$ with retroperitoneal node failure, all the 6 patients $(100 \%)$ with multiple site failure, and all the 4 
Table IV. Clinical outcome of patients according to the prognostic variables.

\begin{tabular}{|c|c|c|c|c|c|c|}
\hline \multirow[t]{2}{*}{ Variables Pts } & \multicolumn{2}{|c|}{ PFS } & \multirow[t]{2}{*}{$p$-Value } & \multicolumn{2}{|c|}{ OS } & \multirow[t]{2}{*}{$p$-Value } \\
\hline & 2-year & 5 -year & & 2-year & 5 -year & \\
\hline \multicolumn{7}{|l|}{ Age (years) } \\
\hline$\leq 64$, pts: 44 & $69.0 \%$ & $58.6 \%$ & 0.166 & $83.2 \%$ & $62.4 \%$ & 0.303 \\
\hline$>64$, pts: 38 & $56.8 \%$ & $41.0 \%$ & & $81.9 \%$ & $52.5 \%$ & \\
\hline \multicolumn{7}{|l|}{ FIGO stage } \\
\hline $\mathrm{IIIC}_{1} 54$ & $57.2 \%$ & $43.4 \%$ & 0.103 & $79.2 \%$ & $50.3 \%$ & 0.119 \\
\hline $\mathrm{IIIC}_{2} 28$ & $74.1 \%$ & $64.8 \%$ & & $89.3 \%$ & $74.0 \%$ & \\
\hline \multicolumn{7}{|l|}{ Tumor grade } \\
\hline $\mathrm{G}_{1-2} 38$ & $69.7 \%$ & $50.5 \%$ & 0.738 & $83.0 \%$ & $63.3 \%$ & \\
\hline $\mathrm{G}_{3} 44$ & $57.8 \%$ & $51.7 \%$ & & $82.5 \%$ & $54.0 \%$ & \\
\hline \multicolumn{7}{|l|}{ Histological type } \\
\hline E 58 & $74.6 \%$ & $62.0 \%$ & $<0.0001$ & $88.7 \%$ & $69.3 \%$ & 0.001 \\
\hline NE 24 & $33.8 \%$ & $22.6 \%$ & & $67.3 \%$ & $31.1 \%$ & \\
\hline \multicolumn{7}{|l|}{ Myometrial invasion } \\
\hline$<50 \% 12$ & $73.3 \%$ & $64.2 \%$ & 0.410 & $91.7 \%$ & $64.2 \%$ & 0.335 \\
\hline$\geq 50 \% 70$ & $61.7 \%$ & $48.5 \%$ & & $81.2 \%$ & $57.4 \%$ & \\
\hline \multicolumn{7}{|l|}{ LVSI } \\
\hline No 24 & $72.7 \%$ & $57.4 \%$ & 0.310 & $85.9 \%$ & $61.4 \%$ & 0.461 \\
\hline Yes 58 & $59.8 \%$ & $48.6 \%$ & & $81.4 \%$ & $57.0 \%$ & \\
\hline \multicolumn{7}{|l|}{ Cervical involvement } \\
\hline No 58 & $65.2 \%$ & $49.7 \%$ & 0.913 & $84.9 \%$ & $66.1 \%$ & 0.143 \\
\hline Yes 24 & $59.6 \%$ & $54.6 \%$ & & $86.7 \%$ & $76.4 \%$ & \\
\hline \multicolumn{7}{|l|}{ Adnexal involvement } \\
\hline No 64 & $66.8 \%$ & $51.4 \%$ & 0.777 & $86.5 \%$ & $72.0 \%$ & 0.610 \\
\hline Yes 18 & $51.7 \%$ & $51.7 \%$ & & $81.7 \%$ & $59.0 \%$ & \\
\hline \multicolumn{7}{|l|}{ Hysterectomy } \\
\hline type I 53 & $62.3 \%$ & $46.4 \%$ & 0.459 & $80.6 \%$ & $52.0 \%$ & 0.212 \\
\hline type II 29 & $65.4 \%$ & $57.9 \%$ & & $86.0 \%$ & $67.4 \%$ & \\
\hline \multicolumn{7}{|l|}{ Postoperative therapy } \\
\hline CT+EBRT 50 & $67.0 \%$ & $54.0 \%$ & 0.483 & $84.6 \%$ & $65.4 \%$ & 0.229 \\
\hline CT 21 & $65.9 \%$ & $54.9 \%$ & & $74.8 \%$ & $54.9 \%$ & \\
\hline RT 11 & $45.5 \%$ & $34.1 \%$ & & $90.0 \%$ & $40.0 \%$ & \\
\hline \multicolumn{7}{|l|}{ CT regimen* } \\
\hline Platinum/PTX 49 based & $71.1 \%$ & $65.8 \%$ & 0.038 & $84.1 \%$ & $66.7 \%$ & 0.190 \\
\hline Platinum 22 based & $57.8 \%$ & $33.7 \%$ & & $76.6 \%$ & $52.6 \%$ & \\
\hline
\end{tabular}

*Among the 71 patients who received adjuvant CT + or-EBRT. Pts: Patients; PFS: progression-free survival; OS: overall survival; G: grade; E: endometrioid; NE: non-endometrioid; LVSI: lymph-vascular space involvement; CT: chemotherapy; EBRT: external beam irradiation; RT: radiotherapy (EBRT and /or brachytherapy, without chemotherapy); PTX: paclitaxel.

patients $(100 \%)$ with isolated vaginal failure died of disease. Three of these latter had previously undergone adjuvant pelvic EBRT (followed by brachytherapy in one case).

Five-year PFS and 5-year OS of the 82 patients were $51.1 \%$ and $59.8 \%$, respectively. PFS and OS were significantly better in patients with endometrioid than in those with non-endometrioid tumors $(p<0.0001$ and $p=0.001$ ) (Table IV). There was a trend towards a better PFS and OS in patients who underwent adjuvant chemotherapy or adjuvant chemotherapy followed by EBRT compared to those who received radiotherapy alone.

Among the patients who received adjuvant chemotherapy with or without EBRT, there was a significantly better PFS $(p=0.0038)$ and a trend to a better OS for the patients who received platinum/paclitaxel-based regimens compared to those who received platinum-based chemotherapy.

\section{Discussion}

Although node involvement is a strong prognostic variable for endometrial cancer, the therapeutic potential of lymphadenectomy in this malignancy is still a matter of debate $(8-10,15,28,30,31,33,37,38)$. According to the recommendations of ESMO-ESGO-ESTRO Consensus Conference regarding apparent stage I endometrioid endometrial cancer, lymphadenectomy: i) is not indicated 
Table V. Studies investigating adjuvant chemotherapy in patients with node-positive endometrial cancer.

\begin{tabular}{|c|c|c|c|c|}
\hline Authors (ref.) & Patients (n.) & Stage histology & Adjuvant treatment & Clinical outcome \\
\hline Watari (16) & 33 & IIIC E, NE & $\mathrm{CT}^{1}$ & $\begin{array}{c}5-\mathrm{y} \text { OS } \\
\mathrm{IIIC}_{1}=86.4 \% \\
\mathrm{IIIC}_{2}=48.1 \%, p=0.01\end{array}$ \\
\hline Fugjimoto (17) & 63 & IIIC E,NE & $\mathrm{CT}^{2}$ & $\begin{array}{l}5-\mathrm{y} \text { OS } \\
\text { Pelvic + aortic LDN (n.38) } 69.1 \% \\
\text { Pelvic LDN (n.25) 53.9\% } p=\mathrm{ns}\end{array}$ \\
\hline Sueoka (28) & 80 & IIIC E, NE & $\mathrm{CT}^{3}$ & $\begin{array}{c}5-\mathrm{y} \text { OS } \\
\text { any } \mathrm{N}+: 76 \% \\
1-2 \mathrm{~N}+: 84.8 \%, p=0.01 \\
\geq 3 \mathrm{~N}+: 57.8 \%\end{array}$ \\
\hline Young (30) & 43 & IIIC E, NE & $\mathrm{CT}^{4} \rightarrow \mathrm{BCT}$ & $\begin{array}{c}\text { 3-year DFS: } 63.6 \% \text {, } \\
\text { 3-year OS: } 78.0 \%\end{array}$ \\
\hline
\end{tabular}

${ }^{1} \mathrm{DOX}+\mathrm{CDDP}+\mathrm{CTX} ;{ }^{2} \mathrm{DOX}+\mathrm{CDDP} \pm \mathrm{CTX} ; \mathrm{CBDCA}+\mathrm{PTX} ;{ }^{3} \mathrm{DOX}+\mathrm{CDDP} ; \mathrm{DOX}+\mathrm{CDDP}+\mathrm{CTX} ; \mathrm{IFO}+\mathrm{DOX}+\mathrm{CDDP} ; \mathrm{CBDCA}+\mathrm{PTX} ;{ }^{4} \mathrm{CBDCA}$ + PTX. ref: Reference; n: number; E: endometrioid; NE: non-endometrioid; CT: chemotherapy; OS: overall survival; LDN: lymphadenectomy; N: node; BCT: brachytherapy; DFS: disease-free survival; OX: doxorubicin; CDDP: cisplatin; CTX: cyclophosphamide; CBDCA: carboplatin; PTX: paclitaxel; IFO: ifosfamide.

for low-risk disease (G1-2 and myometrial invasion $<50 \%)$; ii) can be considered for staging purposes for intermediaterisk disease (myometrial invasion $>50 \%$ or G3; iii) and should be indicated for high- risk disease (G3 with myometrial invasion $>50 \%$ ) (3). Moreover, lymphadenectomy is recommended for clinical or intra-operative stage II endometrioid endometrial cancer as well as for apparent stage I non-endometrioid endometrial cancer. When performed, systematic removal of pelvic and para-aortic nodes should be carried out up to renal veins. Two retrospective studies comparing two nodal assessment approaches in patients with endometrioid endometrial cancer treated at the Majo Clinic and at the Memorial Sloan Kettering Cancer Center showed that the sentinel lymph node algorithm and lymphadenectomy algorithm had the same oncologic outcome in low-risk patients and similar nodal metastasis detection rates in high- risk patients $(39$, 40). Other studies have confirmed that sentinel node mapping can represent a safe, alternative option to minimize lymph node dissection without compromising surgical staging of endometrial cancer $(41,42)$. However, according to the ESMO-ESGO-ESTRO guidelines, sentinel node biopsy is still experimental in endometrial cancer (3).

Data from literature have shown that 5-year-OS ranges from $53.9 \%$ to $81.0 \%$ in stage IIIC, and from $61 \%$ to $86.4 \%$ in Stage IIIC1 and from $42.3 \%$ to $66.3 \%$ in stage IIIC $_{2}$ (6, $16,17,25,27-29,33)$.

Many authors have investigated the role of adjuvant radiotherapy and/or chemotherapy in early-stage, high-risk or advanced-stage endometrial cancer $(11,18-22,33,34,43)$. Only few papers have analyzed the results of postoperative radiotherapy selectively in stage IIIC disease (13, 27, 32). The analysis of the 2177 women with stage IIIC endometrial carcinoma $\left(\mathrm{IIIC}_{1}=1363, \mathrm{IIIC}_{2}=658\right)$ included in the Surveillance, Epidemiology, and End Results (SEER) database from 2004 to 2012 found that 1248 (60\%) had undergone adjuvant radiotherapy (32). The 3-year OS was $80.5 \%$ and $67.6 \%$, for the patients who received radiotherapy and for those who did not, respectively $(p<0.001)$, and the use of this adjuvant treatment was an independent prognostic variable for OS [Hazard ratio $(\mathrm{HR})=0.61,95 \%$ Confidence interval $(\mathrm{CI})=0.51-0.74]$ at multivariate analysis.

Recently adjuvant chemotherapy has been more and more employed in endometrial cancer. Meta-analysis of four randomized trials comparing chemotherapy versus radiotherapy after surgery in 1326 patients with high-risk early or advanced disease showed that chemotherapy was associated with a relative risk (RR) of death at 5 years of 0.87 (95\% CI=0.76-0.99) (19-21, 44, 45). However, the statistical significance was lost, after omission of the GOG 122 study, which was not a pure adjuvant trial because it included also patients with residual disease up to $2 \mathrm{~cm}$.

Four studies assessing adjuvant chemotherapy alone in patients with node positive endometrial cancer reported 5year OS rates ranging from $48.1 \%$ to $84.8 \%$ (Table V).

Young et al. (30) reported that tumor relapsed in 8 of the $25(32.0 \%)$ with stage IIIC $_{1}$ disease and in 7 of the 18 $(38.9 \%)$ with stage IIIC $_{2}$ disease. Failure involved pelvic area, para-aortic area, pelvic plus para-aortic area, and distant sites in $1(4 \%), 3(12 \%), 3(12 \%)$, and $2(8 \%)$ of stage IIIC $_{1}$ patients, and, respectively, in 1 (5.6\%), 2 $(11.1 \%), 1(5.6 \%)$, and $3(16.7 \%)$ of stage IIIC $_{2}$ patients. 
Table VI. Studies investigating adjuvant chemotherapy, radiotherapy and chemotherapy+radiotherapy in patients with node-positive endometrial cancer.

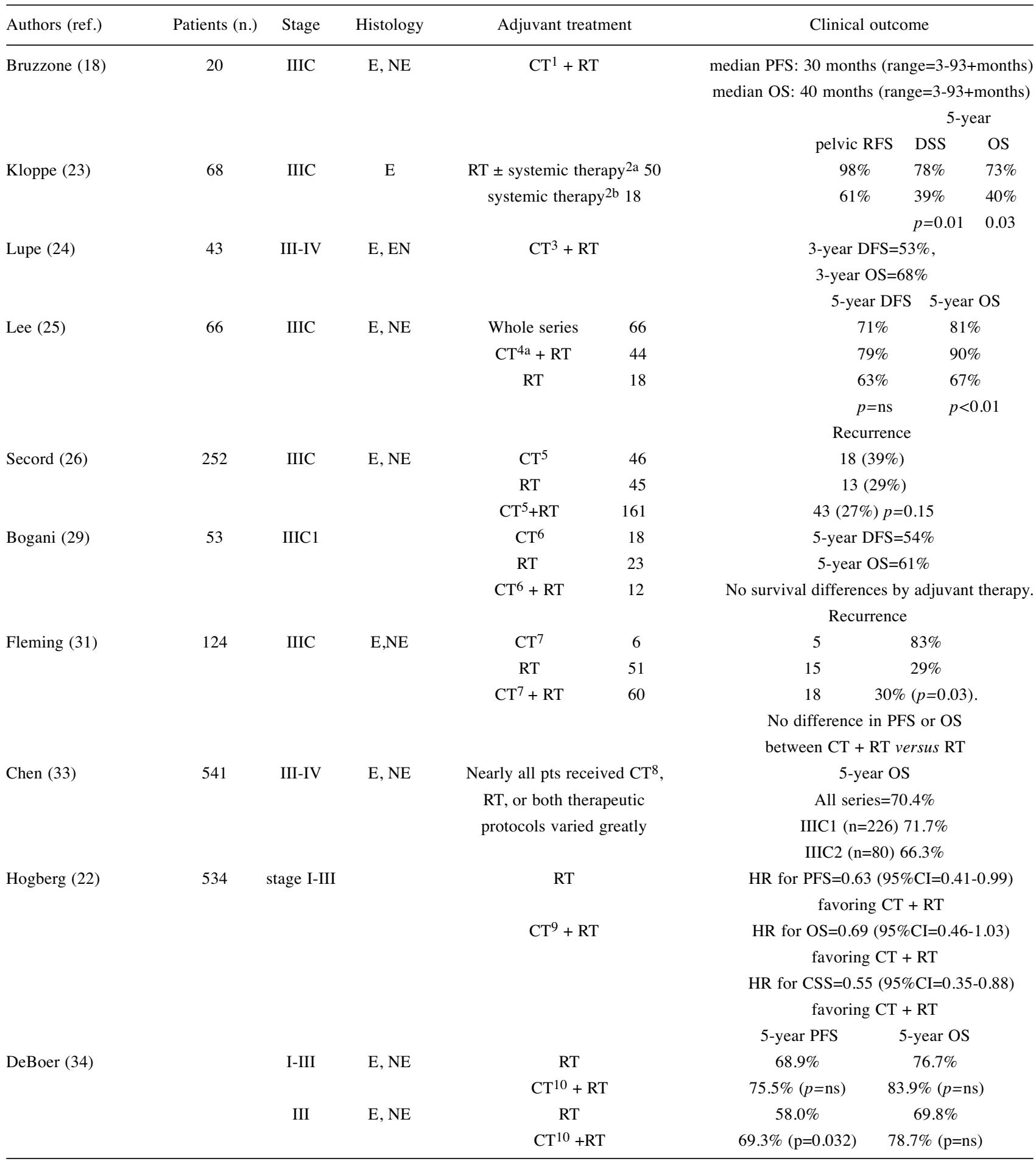

${ }^{1} \mathrm{EPI}$ DOX+ CDDP+ CTX; ${ }^{2 \mathrm{a} D O X}+\mathrm{CDDP}+\mathrm{CTX} ; \mathrm{CBDCA}+\mathrm{PTX} ; \mathrm{HT} ;{ }^{2 \mathrm{~b} D O X}+\mathrm{CDDP}+\mathrm{CTX} ; \mathrm{CBDCA}$; HT; ${ }^{3} \mathrm{CBDCA}+\mathrm{PTX} ;{ }^{4} \mathrm{CBDCA}+\mathrm{PTX}$; $\mathrm{PTX}+\mathrm{DOX}+\mathrm{CTX}$; CDDP+DOX; CDDP+ PTX; ${ }^{5} \mathrm{CBDCA}+\mathrm{PTX}$; PTX+DOX+CDDP; CBDCA+PTX+BEV; CBDCA+PTX+PLD; PTX+CDDP; other $\mathrm{CT}$; ${ }^{6}$ Different combinations of CBDCA or CDDP, PTX, EPIDOX; ${ }^{7} \mathrm{CBDCA}+\mathrm{PTX} ;{ }^{8} \mathrm{CT}$ regimens not specified; ${ }^{9} \mathrm{DOX} / \mathrm{EPIDOX}+\mathrm{CDDP}$; PTX+DOX/EPIDOX +CBDCA; CBDCA+PTX; ${ }^{10}$ CBDCA+PTX. Ref: Reference; n: number; E: endometrioid; NE: non-endometrioid; CT: chemotherapy; RT: radiotherapy; PFS: progression-free survival; OS: overall survival; RFS: recurrence free survival; DSS: disease specific survival; HR: hazard ratio; 95\%CI: 95\% confidence interval; ns: not significant; EPIDOX: epidoxorubicin; CDDP: cisplatin; CTX: cyclophosphamide; DOX: doxorubicin; PTX: paclitaxel; HT: hormone therapy; CBDCA: carboplatin; BEV: bevacizumab; PLD: pegylated liposomal DOX. 
Table VI shows the studies investigating adjuvant chemotherapy, radiotherapy and chemotherapy plus radiotherapy in patients with node- positive endometrial cancer.

In the study of Klopp et al. (23) tumor failure involving vagina, pelvic area, para-aortic area, and distant sites developed in $4(22.2 \%), 4(22.2 \%), 2(11.1 \%)$ and $2(11.1 \%)$ of the 18 patients treated with systemic therapy without external radiotherapy, versus 5 (10.0\%), 1 (2.0\%), $3(6.0 \%)$, and $13(26.0 \%)$ of the 50 patients who received external radiotherapy with or without systemic therapy.

Adjuvant platinum-based chemotherapy interposed with radiotherapy was administered to 43 patients with advanced endometrial cancer (24). The majority had stage IIIC disease $(63 \%)$. Twenty-one patients $(49 \%)$ relapsed at a median time of 17 months, and recurrent disease was local in 2 patients $(9.5 \%)$, distant in $18(85.7 \%)$, and local+distant in 1 patient $(4.8 \%)$. Sixty-two $(94 \%)$ out of 66 patients assessed by Lee and Viswanathan (25) received adjuvant radiotherapy with or without chemotherapy. Seventeen patients $(25.8 \%)$ recurred after a median time of 21 months. PFS and OS were better for patients treated with chemotherapy plus radiotherapy compared to those who received radiotherapy alone.

The sites of failures were vaginal in $10(14 \%)$, pelvic in 7 (9\%), extra-pelvic in $52(70 \%)$, and not specified in $5(7 \%)$ of the 262 patients with stage IIIC disease treated by Secort et al. (26), with no significant differences in overall recurrence rates according to adjuvant therapy. Fleming et al. (31) found a significantly lower recurrence rate in patients receiving radiotherapy with or without chemotherapy compared to those treated with chemotherapy alone.

In a large Taiwanese study, 174 of 541 patients $(32.2 \%)$ with advanced endometrioid endometrial cancer developed a recurrence, which was local in $47(27.0 \%)$, distant in $79(45.4 \%)$, and both local and distant in 48 (27.5\%) (33). Paclitaxel-based multimodality treatment was an independent prognostic factor for better PFS $(\mathrm{HR}=0.608$; 95\% CI $=0.403$ $0.916)$ and $\mathrm{OS}(\mathrm{HR}=0.482 ; 95 \% \mathrm{CI}=0.310-0.749)$.

Recent randomized phase III trials showed that addition of adjuvant chemotherapy to radiotherapy prolongs PFS compared to radiotherapy alone in patients with high-risk profile $(22,34)$. For instance, in the PORTEC 3 trial the combined treatment significantly improved 5-year PFS by $11 \%$ (69.3\% versus $58.0 \%, p=0.032)$ (34).

In our study, endometrial cancer relapsed in $43.9 \%$ of 82 patients, after a median time of 13.5 months, and recurrent disease involved vagina in $6.1 \%$, pelvic nodes in $9.8 \%$, paraaortic nodes in $19.5 \%$, and distant sites in $20.7 \%$ of the patients, respectively. The rates, times and sites of relapses are in agreement with the literature $(23,24,26,30,33)$. In our series, PFS and OS were significantly better in patients with endometrioid tumors than in those with nonendometrioid tumors. Similarly, Sueoka et al. (28) detected a 5-year OS of $90.2 \%$ for endometrioid carcinomas versus $56.7 \%$ for non-endometrioid carcinomas $(p=0.0016)$, and Young et al. (30) reported a better 3-year PFS and 3-year OS for endometrioid than for non-endometrioid tumors $(92.4 \%$ versus $58.0 \%, p=0.001$, and, respectively, $97.2 \%$ versus $65.8 \%, p=0.002)$. Conversely other authors failed to detect a prognostic relevance for histologic type $(16,17)$. In the present investigation, depth of myometrial invasion, tumor grade, LVSI, cervical involvement and adnexal involvement were not related to the PFS and OS. However, literature data about the prognostic relevance of these variables in stage IIIC endometrial cancer are controversial. Several authors reported that myometrial invasion and adnexal involvement did not correlate with the clinical outcome $(16,17,25)$. High tumor grade was associated with worse prognosis in the study of Fujimoto et al. (17) but not in others $(16,25)$, cervical involvement got worse PFS and OS in the study of Lee et al. (25) but not in others $(16,17)$, and LVSI correlated with unfavorable outcome in the series of Watari et al. (16) but not in others $(17,25)$.

In conclusion, patients with FIGO stage IIIC1-IIIC2 endometrial cancer relapsed in $43.9 \%$ of the cases, and distant sites and para-aortic nodes represented the common sites of recurrence. There was a trend towards a better outcome in patients who underwent adjuvant chemotherapy or adjuvant chemotherapy followed by EBRT compared to those who received radiotherapy alone. Among the patients who received adjuvant chemotherapy with or without EBRT, there was a significantly better 5-year PFS $(65.8 \%$ versus $33.7 \%, p=0.038$ ) and a trend to a better 5-year OS $(66.7 \%$ versus $52.6 \%)$ for the patients who received platinum/paclitaxel-based regimens compared to those who received platinum-based chemotherapy. However, the retrospective, non-randomized nature of the study and the limited number of patients did not allow to draw any conclusions regarding the impact of adjuvant treatment on the pattern of recurrences.

\section{References}

1 Palomba S, Falbo A, Russo T and Zullo F: Updating of a recent meta-analysis of randomized controlled trials to assess the safety and the efficacy of the laparoscopic surgery for treating early stage endometrial cancer. Gynecol Oncol 114: 135-136, 2009.

2 Walker JL, Piedmonte MR, Spirtos NM, Eisenkop SM, Schlaerth JB, Mannel RS, Barakat R, Pearl ML and Sharma SK: Recurrence and survival after random assignment to laparoscopy versus laparotomy for comprehensive surgical staging of uterine cancer: Gynecologic Oncology Group LAP2 Study. J Clin Oncol 30: 695-700, 2012

3 Colombo N, Creutzberg C, Amant F, Bosse T, González-Martín A, Ledermann J, Marth C, Nout R, Querleu D, Mirza MR and Sessa C: ESMO-ESGO-ESTRO Consensus Conference on endometrial cancer: diagnosis, treatment and follow-up. Int $\mathrm{J}$ Gynecol Cancer 26: 2-30, 2016. 
4 Tanaka T, Terai Y, Hayashi S, Aoki D, Miki M, Kobayashi E, Kimura T, Baba T, Matsumura $\mathrm{N}$ and Ohmichi M: Comparison between laparoscopy and laparotomy in systematic para-aortic lymphadenectomy for patients with endometrial cancer: a retrospective multicenter study. J Gynecol Surg 33: 105-110, 2017.

5 Ind T, Laios A, Hacking $\mathrm{M}$ and Nobbenhuis $\mathrm{M}$ : A comparison of operative outcomes between standard and robotic laparoscopic surgery for endometrial cancer: A systematic review and meta-analysis. Int J Med Robot 13(4): e1851, 2017.

6 Creasman WT, Odicino F, Maisonneuve P, Quinn MA, Beller U, Benedet JL, Heintz AP, Ngan HY and Pecorelli S: Carcinoma of the corpus uteri. FIGO 26th Annual Report on the results of treatment in gynecological cancer. Int J Gynaecol Obstet 95: S105-143, 2006.

7 Creasman W: Revised FIGO staging for carcinoma of the endometrium. Int J Gynaecol Obstet 105: 109, 2009.

8 Frost JA, Webster KE, Bryant A and Morrison J: Lymphadenectomy for the management of endometrial cancer. Cochrane Database Syst Rev 10: CD007585, 2017.

9 Benedetti Panici P, Basile S, Maneschi F, Alberto Lissoni A, Signorelli M, Scambia G, Angioli R, Tateo S, Mangili G, Katsaros D, Garozzo G, Campagnutta E, Donadello N, Greggi S, Melpignano M, Raspagliesi F, Ragni N, Cormio G, Grassi R, Franchi M, Giannarelli D, Fossati R, Torri V, Amoroso M, Crocè $\mathrm{C}$ and Mangioni C: Systematic pelvic lymphadenectomy $v s$. no lymphadenectomy in early-stage endometrial carcinoma: randomized clinical trial. J Natl Cancer Inst 100: 1707-1716, 2008.

10 Kitchener H, Swart AM, Qian Q, Amos C and Parmar MK: Efficacy of systematic pelvic lymphadenectomy in endometrial cancer (MRC ASTEC trial): a randomised study. Lancet 373: 125-136, 2009.

11 Gadducci A and Greco C: The evolving role of adjuvant therapy in endometrial cancer. Crit Rev Oncol Hematol 78: 79-91, 2011.

12 Mariani A, Dowdy SC, Keeney GL, Long HJ, Lesnick TG and Podratz KC: High-risk endometrial cancer subgroups: candidates for target-based adjuvant therapy. Gynecol Oncol 95: 120-126, 2004.

13 Mariani A, Dowdy SC, Cliby WA, Haddock MG, Keeney GL, Lesnick TG and Podratz KC: Efficacy of systematic lymphadenectomy and adjuvant radiotherapy in node-positive endometrial cancer patients. Gynecol Oncol 101: 200-208, 2006.

14 NCCN Clinical Practice Guidelines in Oncology. Uterine Neoplasms. Version 2. 2015 Available at:http://www.nccn.org/ professionals/physician_gls/pdf/uterine.pdf.

15 Fotopoulou C, El-Balat A, du Bois A, Sehouli J, Harter P, Muallem MZ, Krätschell RW, Traut A and Heitz F: Systematic pelvic and paraaortic lymphadenectomy in early high-risk or advanced endometrial cancer. Arch Gynecol Obstet 292: 1321$1327,2015$.

16 Watari H, Todo Y, Takeda M, Ebina Y, Yamamoto R and Sakuragi $\mathrm{N}$ : Lymph-vascular space invasion and number of positive paraaortic node groups predict survival in node-positive patients with endometrial cancer. Gynecol Oncol 96: 651-657, 2005.

17 Fujimoto T, Nanjyo H, Nakamura A, Yokoyama Y, Takano T, Shoji T, Nakahara K, Yamada H, Mizunuma H, Yaegashi N, Sugiyama T, Kurachi H, Sato A and Tanaka T: Para-aortic lymphadenectomy may improve disease-related survival in patients with multipositive pelvic lymph node stage IIIc endometrial cancer. Gynecol Oncol 107: 253-259, 2007.
18 Bruzzone M, Miglietta L, Franzone P, Gadducci A and Boccardo F: Combined treatment with chemotherapy and radiotherapy in high-risk FIGO stage III-IV endometrial cancer patients. Gynecol Oncol 93: 345-352, 2004.

19 Randall ME, Filiaci VL, Muss H, Spirtos NM, Mannel RS, Fowler J, Thigpen JT and Benda JA: Randomized phase III trial of whole-abdominal irradiation versus doxorubicin and cisplatin chemotherapy in advanced endometrial carcinoma: a Gynecologic Oncology Group Study. J Clin Oncol 24: 36-44, 2006.

20 Maggi R, Lissoni A, Spina F, Melpignano M, Zola P, Favalli G, Colombo A and Fossati R: Adjuvant chemotherapy vs radiotherapy in high-risk endometrial carcinoma: results of a randomised trial. Br J Cancer 95: 266-271, 2006.

21 Susumu N, Sagae S, Udagawa Y, Niwa K, Kuramoto H, Satoh $\mathrm{S}$ and Kudo R: Randomized phase III trial of pelvic radiotherapy versus cisplatin-based combined chemotherapy in patients with intermediate- and high-risk endometrial cancer: a Japanese Gynecologic Oncology Group study. Gynecol Oncol 108: 226233, 2008.

22 Hogberg T, Signorelli M, de Oliveira CF, Fossati R, Lissoni AA, Sorbe B, Andersson H, Grenman S, Lundgren C, Rosenberg P, Boman K, Tholander B, Scambia G, Reed N, Cormio G, Tognon G, Clarke J, Sawicki T, Zola P and Kristensen G: Sequential adjuvant chemotherapy and radiotherapy in endometrial cancerresults from two randomised studies. Eur J Cancer 46: 24222431,2010

23 Klopp AH, Jhingran A, Ramondetta L, Lu K, Gershenson DM and Eifel PJ: Node-positive adenocarcinoma of the endometrium: outcome and patterns of recurrence with and without external beam irradiation. Gynecol Oncol 115: 6-11, 2009.

24 Lupe K, D'Souza DP, Kwon JS, Radwan JS, Harle IA, Hammond JA and Carey MS: Adjuvant carboplatin and paclitaxel chemotherapy interposed with involved field radiation for advanced endometrial cancer. Gynecol Oncol 114: 94-98, 2009.

25 Lee LJ and Viswanathan AN: Combined chemotherapy and radiation improves survival for node-positive endometrial cancer. Gynecol Oncol 127: 32-37, 2012.

26 Secord AA, Geller MA, Broadwater G, Holloway R, Shuler K, Dao NY, Gehrig PA, O'Malley DM, Finkler N and Havrilesky LJ: A multicenter evaluation of adjuvant therapy in women with optimally resected stage IIIC endometrial cancer. Gynecol Oncol 128: 65-70, 2013.

27 Rajasooriyar C, Bernshaw D, Kondalsamy-Chennakesavan S, Mileshkin L and Narayan K: The survival outcome and patterns of failure in node positive endometrial cancer patients treated with surgery and adjuvant radiotherapy with curative intent. J Gynecol Oncol 25: 313-319, 2014.

28 Sueoka K, Umayahara K, Abe A, Usami T, Yamamoto A, Nomura H, Matoda M, Okamoto S, Omatsu K, Kondo E, Kato $\mathrm{K}$ and Takeshima N: Prognosis for endometrial cancer patients treated with systematic pelvic and para-aortic lymphadenectomy followed by platinum-based chemotherapy. Int J Gynecol Cancer 25: 818-826, 2015.

29 Bogani G, Cromi A, Serati M, Di Naro E, Donadello N, Casarin J, Nardelli F and Ghezzi F: Chemotherapy reduces para-aortic node recurrences in endometrial cancer with positive pelvic and unknown para-aortic nodes. Int J Gynecol Cancer 25: 263-268, 2015. 
30 Young MR, Higgins SA, Ratner E, Yu JB, Mani S, Silasi DA, Azodi M, Rutherford T, Schwartz PE and Damast S: Adjuvant carboplatin, paclitaxel, and vaginal cuff brachytherapy for stage III endometrial cancer: analysis of outcomes and patterns of recurrence based on pathologic characteristics. Int J Gynecol Cancer 25: 431-439, 2015.

31 Fleming ND, Soliman PT, Westin SN, dos Reis R, Munsell M, Klopp AH, Frumovitz M, Nick AM, Schmeler K and Ramirez PT: Impact of lymph node ratio and adjuvant therapy in nodepositive endometrioid endometrial cancer. Int J Gynecol Cancer 25: 1437-1444, 2015

32 Shaikh T, Churilla TM, Mantia-Smaldone GM, Chu C, Rubin SC and Anderson PR: The role of adjuvant radiation in lymph node positive endometrial adenocarcinoma. Gynecol Oncol 141: 434439, 2016.

33 Chen JR, Chang TC, Fu HC, Lau HY, Chen IH, Ke YM, Liang YL, Chiang AJ, Huang CY, Chen YC, Hong MK, Wang YC, Huang KF, Hsiao SM and Wang PH: Outcomes of patients with surgically and pathologically staged IIIA-IVB pure endometrioidtype endometrial cancer: a Taiwanese Gynecology Oncology Group (TGOG-2005) retrospective cohort study (A STROBECompliant Article). Medicine (Baltimore) 95: e3330, 2016.

34 de Boer SM, Powell ME, Mileshkin LR, Katsaros D, Bessette $\mathrm{P}$ and Haie-Meder: Final results of the international randomized PORTEC-3 trial of adjuvant chemotherapy and radiation therapy (RT) versus RT alone for women with high-risk endometrial cancer. J Clin Oncol 35: Abstract 5502, 2017.

35 Gadducci A, Cosio S, Fabrini MG, Guerrieri ME, Greco C and Genazzani AR: Analysis of failures in patients with FIGO stage IIIc1-IIIc2 endometrial cancer. Anticancer Res 32: 201-205, 2012.

36 Carrara L, Gadducci A, Landoni F, Maggino T, Scambia G, Galletto L, Lissoni AA, Fuso L, Zola P and Sartori E: Could different follow-up modalities play a role in the diagnosis of asymptomatic endometrial cancer relapses?: an Italian multicentric retrospective analysis. Int J Gynecol Cancer 22: 1013-1019, 2012.

37 Zhou J, He ZY, Li FY, Sun JY, Lin HX, Wu SG and Chen QH: Prognostic value of lymph node ratio in stage IIIC epithelial ovarian cancer with node-positive in a SEER population-based study. Oncotarget 7: 7952-7959, 2016.

38 Kikuchi A, Yanase T, Sasagawa M and Honma S: The role of para-aortic lymphadenectomy in stage IIIC endometrial cancer: A single-institute study. J Obstet Gynaecol 37: 510-513, 2017.
39 Zahl Eriksson AG, Ducie J, Ali N, McGree ME, Weaver AL, Bogani G, Cliby WA, Dowdy SC, Bakkum-Gamez JN, AbuRustum NR, Mariani A and Leitao MM Jr.: Comparison of a sentinel lymph node and a selective lymphadenectomy algorithm in patients with endometrioid endometrial carcinoma and limited myometrial invasion. Gynecol Oncol 140: 394-399, 2016.

40 Ducie JA, Eriksson AGZ, Ali N, McGree ME, Weaver AL, Bogani G, Cliby WA, Dowdy SC, Bakkum-Gamez JN, Soslow RA, Keeney GL, Abu-Rustum NR, Mariani A and Leitao MM Jr.: Comparison of a sentinel lymph node mapping algorithm and comprehensive lymphadenectomy in the detection of stage IIIC endometrial carcinoma at higher risk for nodal disease. Gynecol Oncol 147: 541-548, 2017.

41 Kim TH, Kim HS, K TJ, Chang SJ, Kim DY, Ryu SY, Kim BG, Kim YT, Bae DS, Ryu HS and Nam JH: Survival impact based on the thoroughness of pelvic lymphadenectomy in intermediateor high-risk groups of endometrioid-type endometrial cancer: A multi-center retrospective cohort analysis. Gynecol Oncol 141: 440-446, 2016.

42 Rossi EC, Kowalski LD, Scalici J, Cantrell L, Schuler K, Hanna RK, Ade M, Ivanova A and Boggess JF: A comparison of sentinel lymph node biopsy to lymphadenectomy for endometrial cancer staging (FIRES trial): a multicentre, prospective, cohort study. Lancet Oncol 18: 384-392, 2017.

43 Gadducci A, Cosio S, Landoni F, Maggino T, Zola P, Sostegni B, Bellicini A, Fuso L, Cristofani R and Sartori E: Adjuvant treatment and analysis of failures in patients with high-risk FIGO Stage Ib-II endometrial cancer: an Italian multicenter retrospective study (CTF study). Gynecol Oncol 134: 29-35, 2014.

44 Wolfson AH, Brady MF, Rocereto T, Mannel RS, Lee YC, Futoran RJ, Cohn DE and Ioffe OB: A gynecologic oncology group randomized phase III trial of whole abdominal irradiation (WAI) vs. cisplatin-ifosfamide and mesna (CIM) as post-surgical therapy in stage I-IV carcinosarcoma (CS) of the uterus. Gynecol Oncol 107: 177-185, 2007.

45 Johnson N, Bryant A, Miles T, Hogberg T and Cornes P: Adjuvant chemotherapy for endometrial cancer after hysterectomy. Cochrane Database Syst Rev 10: CD003175, 2011.

Received December 28, 2017

Revised January 23, 2018

Accepted January 24, 2018 